\title{
MEMORÍA, A FLECHA QUE RASURA O TEMPO: REFLEXÕES CONTRACOLONIAIS DESDE UMA FILOSOFIA AFRICANA E A RECUPERAÇÃO DAS MEMÓRIAS USURPADAS PELO COLONIALISMO
}

\author{
MEMORÍ(Y), THE ARROW THAT BREAKES TIME: COUNTER- \\ COLONIAL REFLECTIONS FROM AN AFRICAN PHILOSOPHY AND \\ THE RECOVERY OF MEMORIES USURPED BY COLONIALISM
}

\author{
Francisco Phelipe Cunha Paz \\ Recebido em: 07/2019 \\ Aprovado em: 09/2019
}

\begin{abstract}
Resumo: Este ensaio tem como ponto de partida o entendimento de que as Filosofia(s) Africana(s) são um conhecimento já estabelecido que permite a construção de novos conceitos e no questionamento dos mesmos, tanto para a filosofia, como para a história e os estudos da memória. No contexto das experiências negro-africanas na diáspora, no Brasil especificamente, a memória foi e pode continuar sendo um poderoso instrumento de manutenção do imaginário colonialista-racista. Diante disso faremos algumas considerações a respeito do conceito de MemÓRÍa como o elo mais profundo com as ancestralidades, como possibilidade de reconstrução do ser negro na diaspórico, de se transformar e sair em agência de seu ser e estar no mundo, das suas memórias, seus sentidos, usos e significados. MemÓRÍa como possibilidade de restituir a lembrança, a memória e a história do ser africano e seus descendentes negros na diáspora, aos próprios negros, recuperando memórias e identidades usurpadas pelo colonialismo.
\end{abstract}

Palavras-Chaves: Filosofias Africanas; Passado; Memória, Identidades; MemORÍa.

\begin{abstract}
This essay has as its starting point, the refusal to understand that the studies of African Philosophy are limited to the exercise of justification of what is "African Philosophy", or the relevance of its studies, and the alignment with the understanding that African Philosophy (s). (s) are a knowledge already established and that allows the construction of new concepts and the questioning of them both for philosophy, for history and studies of memory. In the context of black African experiences in the diaspora, in Brazil specifically, memory was and can continue to be a powerful instrument for maintaining the colonialist-racist imagination. Given this we will make some considerations about the concept of Memory as the deepest link with ancestry, as a possibility of reconstruction of the black being in the diasporic, to transform and leave in agency of their being and being in the world, their memories, their senses, uses and meanings. Memory as the possibility of restoring the memory, memory and history of the African being and his black descendants in the diaspora, to blacks themselves, recovering memories and identities usurped by colonialism.
\end{abstract}

Key-words: African Philosophy; Past; Memory; Identity; MemORÍa

\footnotetext{
${ }^{1}$ Historiador, Mestre em Preservação do Patrimônio Cultural/Iphan e Mestre em Desenvolvimento, Sociedade e Cooperação Internacional/UnB. Integrante do Núcleo de Estudos de Filosofia Africana - NEFA/UnB e do Grupo de Estudos sobre Afrorreligiões - Calundu/UnB.
} 
Há sulcos em sua face

que são caminhos do mundo.

(Beatriz Nascimento - Sonho)

\section{Travessia, o lastro da pemba branca}

O Brasil é a escravização de povos negros africanos. Seja naquilo que o limita, seja naquilo que o torna potência criativa e inventiva. Não só foi o último território das Américas a abolir a escravidão como aquele que mais recebeu africanos escravizados. O país conviveu por mais de três séculos com a tragédia da escravização de negros e negras africanos e de um ataque à dignidade humana desses sujeitos. Evento que tem sido amplamente denunciado por um lado e comemorado por outro, além de por vezes ser negado e/ou silenciado.

Após passados 130 anos da abolição da escravatura muitos são os esforços para converter a escravidão em um traço do passado, obsoleto e distante no tempo, mas muitos são também os esforços e as agências, sobretudo, de povos e comunidades negras, em produzir maneiras próprias de lembrar, narrar e fazer usos das memórias e do passado da escravidão negra no Brasil. Atualmente tem se presenciado cada vez mais a disputa da invenção do presente e de um projeto de futuro gestado nas disputas das narrativas sobre o passado, "Lembrar é por isso mesmo, exercício de rebeldia; de não deixar passar e de ficar para contar" (SCHWARTZ \& GOMES, 2018, p.19).

Considerando a imprecisão dos dados sobre o tráfico e o comércio de escravizados, muito por conta da própria dinâmica dessa escravidão mercantil, estima-se que cerca 4,8 milhões de africanos desembarcaram no Brasil entre 1550 e 1860. Capturados, embarcados e transladados de maneira desumana, os escravizados enfrentavam cerca de sessenta dias no mar em condições insalubres, péssimas condições de higiene, dieta precária, sofrendo com desnutrição, febre, disenteria e outras doenças. O cuidado com a saúde desses escravizados só existiam quando chegavam nos portos americanos, onde eram inspecionados por uma equipe médica a fim de evitar contaminação da população livre das cidades.

A documentação pouco diz [isso também se fez presente por muito tempo na historiografia brasileira] sobre as origens desses africanos e africanas escravizadas, mas devido as características de desumanização do tráfico, omitir tal informação, ou torná-la imprecisa por desdém, ajudou a reforçar a ideia do escravizado como um corpo sem memória, sem passado, sem história. As principais origens, etnias e povos listados por Rugendas (1998) e Debret, por 
exemplo, são: Benguelas, Minas, Nganguelas, Cabindas, Minas nagô, Congos e Moçambiques (DEBRET, s/dp.227).

O exercício de relembrar o tráfico e a escravidão mercantil passa pela procura em desvendar elementos a respeito da África Central [Angola, os dois Congos] e a África Ocidental [Gana, Togo, Benim, Nigéria], as semelhanças e diferenças dos africanos que aqui chegaram. Passa por desfazer as naturalizações e generalizações dos manuais didáticos que insistem na narrativa de uma escravidão que começa com o açúcar, passa pelo ouro e termina com o café, passar por desvelar o cotidiano, as realidades sociais, culturais, as experiências de negras e negros escravizados e como estes produziram ou ajudaram a produzir paisagem urbanas e rurais singulares, onde vários símbolos e signos africanos foram sendo importados, criados e recriados.

É ainda, uma tentativa de dar conta das trajetórias tanto de sofrimentos, quanto de afirmação de si, e dos antepassados dos sujeitos escravizados, com o cuidado para que isso não acabe por naturalizar a dor e a barbárie da violência da colonização, ou, romantizar as experiências e existências negro africanas dentro de um lugar que as aprisiona entre a vítima e o resistente. Pensar a travessia como encruzo, aquilo que acontece fora dessa lógica que por vezes não passa de um falso dualismo vazio, entre uma vítima absoluta e um combatente/resistente que apenas sobrevive as ações do colonizador, imagem que pode esconder o complexo sistema cultural criado e recriado nas Américas pelos africanos escravizados.

Para pensar na travessia focamos nas agências que são "sobre viver", como esses sujeitos trouxeram, traduziram e modificaram culturas africanas em terras brasileiras, é pensar na perceptiva do marafo, do jogo, da mandinga, da negociação e também do enfrentamento, das exigências e das concessões, do visível e do invisível. É pensar num legado afrodiaspórico de filosofias, cantos, sons, ritmos, tradições e cosmologias africanas trazidas e recriadas. Para pensar na travessia e desde a travessia, este ensaio aborda uma obra recente e que tem chamado bastante atenção, “60 dias”, do arte-educador e artista plástico negro, Jaime Lauriano. 


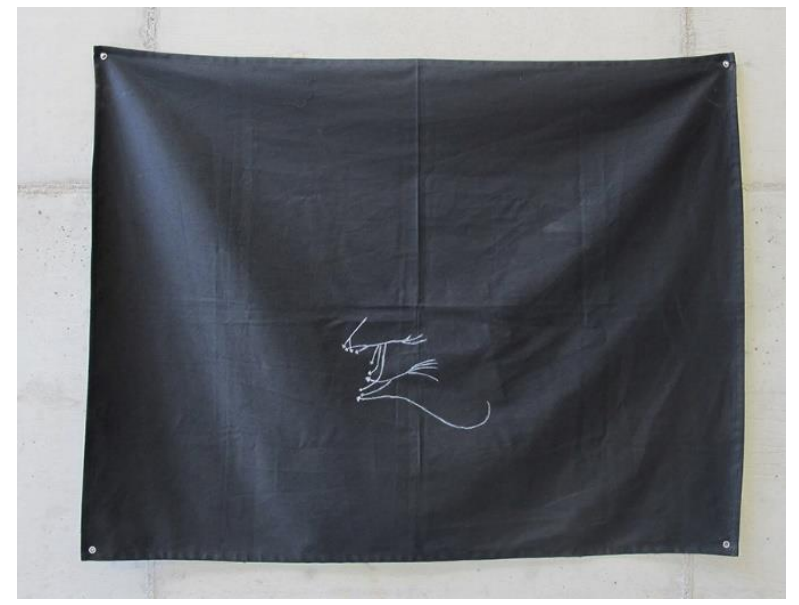

Figura 1: "60 Dias"

Obra de Jaime Lauriano, parte da Obra "Américas", 50x110; pemba branca sobre algodão preto, 2015.

Sessenta dias era o tempo que costumava durar a "travessia" entre o continente africano e o Brasil, dentro de um navio negreiro. O autor busca em suas produções recentes problematizar as estruturas de poder contidas na construção das narrativas históricas. A partir dos painéis que compõem a obra "Américas", é possível questionar quem pode lembrar e quem pode narrar. Qual a importância da memória e das narrativas num país racista, ou ainda, qual a importância de pensarmos uma história e uma memória através da cosmossensação do vasto e complexo repertório cultural africano e afrodiaspórico e não simplesmente procurar o negro nos estudos da memória e da história?

Os seus trabalhos são muito nesse esforço de produção de uma narrativa outra, focada principalmente na desmitificação do ideal racista de democracia racial e na releitura de outros momentos chaves da história do Brasil. Suas referências negro-africanas não estão apenas nos temas das obras, tráfico de africanos escravizados, epistemicídio, genocídio da juventude negra, mas inclusive no material utilizado. O conjunto de obras intitulado "Américas", e "60 dias" é parte delas, é feito com a técnica de desenho com pemba branca [efun/giz branco] e lápis dermatográfico sobre algodão preto.

A pemba [branca] (ou Efun), é algo como cal em kimbundu ou mpemba que seria como giz em kikongo, segundo dicionário banto de Nei Lopes. É um pó retirado do calcário, que não se restringe a cor branca, mas como popularmente se conta e se sabe, era muito utilizado por alguns povos bantos nos rituais de suas tradições. Hoje é muito utilizada na Umbanda e nos Candomblés, por exemplo, onde o neófito, o iniciado, Iyawô, tem seu corpo todo marcado com o efun fun (pó branco). 
Na umbanda é o material utilizado para pretos velhos ou outros encantados riscarem seus pontos, e assim contarem quem são, suas históricas e produzirem encantamentos dos espaços e territórios. Em algumas tradições do candomblé angola brasileiro a pemba e o efun são utilizados para limpar o local num ritual para Mpambu Nzila [Pambo Njila], o senhor dos caminhos, onde o portal que liga o mundo espiritual e material estaria aberto, onde a travessia das energias se encontram. É mais ou menos o que Jaime procura fazer com a pemba branca, risca pontos encantados de outras narrativas contando outras histórias sobre os negro-africanos nas Américas e no Brasil especificamente, limpando o território narrativo para a travessia das ancestralidades.

“60 dias” está aí para nos lembrar que marcos comemorativos, os 130 anos da abolição, por exemplo, aos olhos da História, devem ser investigados a fim de que possamos entender de que maneira eles servem às diversas operações de sentido, comunicando sobre a produção de sentidos e dos usos do passado por diferentes agentes históricos, ou mesmo, os processos coloniais de produção de esquecimentos e silenciamentos que excluem determinados sujeitos da possibilidade de produzirem seus próprios sentidos e usos do passado e de suas memórias.

Dito isto, qual seria o papel social da história e da filosofia, como se dão as diferentes solicitações para que seus profissionais atuem no espaço público? Como as narrativas históricas ou filosóficas de entendimento de mundo estão sendo reivindicadas para fins de reparação social, cultural, jurídica epistemológica e ontológica?

\section{Desencantamento da memória como desencantamento do ser: memórias usurpadas pelo colonialismo.}

Desde a segunda metade do século XX a memória tem sido um tema muito explorado nos estudos de História e nas humanidades de maneira geral. No contexto das diásporas africanas, a memória tem sido utilizada como um poderoso instrumento de manutenção do imaginário colonialista e racista. $\mathrm{O}$ esquecimento produzido sobre a escravidão, sobre a história, a memória e as heranças negro-africanas está longe de ser fruto de um acaso, é antes um projeto (CUNHA PAZ, 2019, p.23). Giselle Beiguelman (2019), em entrevista à Folha de São Paulo² fala em "memoricídios", isto é, um o esforço de produção de apagamentos, silenciamentos, morte da memória, tanto da memória da violência colonial, como a morte da memória das heranças e patrimônios negros ou qualquer traço que possa simbolizar ou potencializar uma resistência a partir do passado.

\footnotetext{
${ }^{2}$ http://abre.ai/daescravidaoaditadura
} 
É latente, nos dias de hoje, o quanto o Brasil tem muitas dificuldades de lidar com as memórias e o passado trágico da escravidão, sintoma disso é a pouca identificação desse período como um passado de horror, tragédia e barbárie. Pelo contrário, o esforço secular foi sempre em sepultar essas lembranças, obliterar o passado a esse outro, o negro-africano diaspórico, subalternizado e desumanizado, reforçando na experiência do colonizado a ruptura, a perda de contato com tudo que o pudesse fazer recordar sua própria humanidade. Esse passado, essa memória, precisavam ser esquecidos, o negro precisava ser mantido dentro de um isolamento cultural e ontológico, onde só restaria a ele o mundo do branco, as experiências do “eu-universal branco", ou do "eu-negro" gestado pelo racismo (FANON, 2008).

Nos dias atuais esse sequestro se dá no campo ontológico e epistemológico e permaneceu provocando, entre outras coisas, o desarranjo das memórias, o trauma físico e simbólico, a perda da potência criativa e o esfacelamento do ser de negro africano na experiência da diáspora. As mortes e esquecimento impostos às memórias negras $e$ heranças produziram historicamente a subalternização e descrença sobre os conhecimentos e práticas das populações africanas e seus descendentes, procurando mantê-las sob a clausura da marginalização, da demonização e mesmo da sua criminalização. As estratégias do colonialismo em tentar controlar os mecanismos de produção e gestão das memórias dos povos negros na diáspora, entre lembranças e esquecimentos, é uma das facetas necropolíticas que gesta o não-ser e justifica a morte do ser negro, que é também a possibilidade da morte do corpo biológico, mas, sobretudo, a morte da memória, do passado, da sua história e ancestralidade, e assim a morte dos seus conhecimentos ancestrais (CUNHA PAZ, 2019).

Sabe-se que em alguns lugares do território africano os escravizados eram obrigados a participarem de pequenos "rituais" de morte da memória, como a "árvore do esquecimento". Eram obrigados a dar sucessivas voltas em torno da árvore e esquecer os nomes [muitos eram batizados com nomes cristãos], suas famílias [muitas famílias mesmo que capturadas juntas eram separadas antes de serem embarcadas], lembranças de quem eram. Aos africanos esquecer era a única coisa que deveriam lembrar. Suas experiências, os conhecimentos e as memórias eram lançadas ao mar, que pela sua enormidade e vastidão procurava, aos olhos do colonizador, representar uma espécie de portal do não retorno, de ruptura com suas memórias e heranças, seu complexo cultural, social e cosmológico, partindo ao novo mundo como corpos vazios, desumanizados, bestializados, mortos, dentro de uma perspectiva vitalista de oposição à vida, e mesmo simbólica, de esquecimento como morte (FANON, 2008). 
O colonialismo, a escravidão e o racismo produziam a descredibilidade de inúmeras formas de existências africanas, de seus conhecimentos e assim procuravam produzir também o esquecimento das suas memórias e, por consequência a sua morte, seja ela física [aqueles que recusam o cativeiro em conflito ou que sucumbiam aos negreiros] ou simbólica, através do desvio e esfacelamento existencial. O Sequestro do ser-que-era e a colonização, aprisiona o destino/caminho (odú), isto é, a personalidade, a forma de inscrição de povos africanos nesse "mundo-outro", o "mundo da vida" fora do Ayê. E essa é uma questão central aos nagôs ${ }^{3}$ [e ao seu pensamento], porque há um entendimento de que o destino é irreversível, então, é de suma importância que eles possam poder escolher sua cabeça, seu Orít $^{4}$, isso não implica em um bom ou mal destino, mas na continuidade de uma escolha que é comunitária e que contribui para o bom funcionamento da vida em comunidade e dos laços de solidariedade.

Assim, o sequestro do ser, como metáfora para pensarmos o impacto da colonização sobre o ser negro-africano e afrodiaspórico, é uma ação permanente, que inicia com a colonização e a escravidão, mas que se perpetua com os racismos nos períodos pós-colonial e pós-abolição. É a imposição da morte, do esquecimento como condição da vida, a vida em cativeiro no colonialismo das Américas. O regime colonial, a escravidão e o racismo procuravam destruir a vida da cultura dos povos africanos e ameríndios que como vidas fora do padrão, sub-humanas, eram desumanizadas ou desumanizáveis. Uma das lógicas de ação do colonialismo foi a naturalização desse outro sob essa condição de besta, e de subalternidade (FANON, 2008; AJARI, 2011).

\footnotetext{
${ }^{3}$ Os nagôs no Brasil, também popularmente chamados de "jeje-nagô", são os povos que remete ao Costa da Mina, ao que hoje é a Nigéria e o Benin, antigo Daomé, seriam as nações dos Egbá, Egbádo, Ijebu, Ijexá, Ketu, Sabé, Iaba, Anagô e Eyó, incorporados dos Adja, Fon, Huedá, Mali, jejum e outros povos genericamente conhecidos no Brasil como Jeje. Historicamente foram os últimos a serem traficados para o Brasil adentrando principalmente pelo porto de Salvador. Para Muniz Sodré "nagô tornou-se um nome genérico para a diversidade do complexo cultural, na verdade equivalente a palavra ioruba, designativa dos falantes dessa língua" [...] A insistência na denominação "nagô" -mas também "jeje-nagô" - conota, para nós, a pouca familiaridade brasileira com a diversidade étnica dos escravos" (2017, p. 88-89). A meu ver, distanciamento produzido intencionalmente pela própria colonização e dinâmica da escravidão.

${ }^{4}$ Grafia sugerida por José Benites em Dicionário Yourubá - Português, Rio de Janeiro: Bertrand-Brasil, 2011. Wanderson Flor do Nascimento diz que "Orí é a sede do nosso eu, a marca da nossa individualidade" (2007, p.140). "Cada pessoa [sujeito], em sentido amplo ${ }^{4}$, é compreendida numa perspectiva tripartite e relacional, composta por ara (corpo), emi (mente/alma) e orí ("cabeça interior), diferente das duas últimas dimensões, que são metafísicas/espirituais, a primeira dimensão é física (ADOEFE, 2004; DIAS, 2013). Assim, a existência pessoal é em uma perspectiva africana-iorubana "tanto o resultado de forças divinizadas como naturais" diante de uma anterioridade lógica, histórica e ontológica [a ancestralidade] (OLIVEIRA, 2003, p. 53). A cabeça (orí) como esse elemento de particular atenção, é considerado central na identidade dos sujeitos, portadora do destino [divindade pessoal] e responsável pelo seu pertencimento comunitário, o que reforça "a tamanha crueldade da destruição da identidade perpetrada pela colonização, pois retirou de nossas (os) ancestrais uma parte importante do sentido do seu ser" (NASCIMENTO, 2007, p.140)" (CUNHA PAZ, 2019, p.81).
} 
Essa desumanização é o mecanismo/dispositivo pelo qual a vida desse outro, negro e indígena é determinado como não-humana, é causa e efeito das instituições coloniais (CARNEIRO, 2002). Que só funcionam com esses dois polos, um Eu e Outro bem definidos, claramente determinados, e que suas ontologias são facilmente conhecidas e identificadas, necessariamente entre o bem e o mal, belo e o feio, o branco e o negro, exemplos de um “maniqueísmo delirante" (AJARAI, 2011, p.54).

Assim, o colonialismo procura a todo instante obliterar o passado a esse outro, subalterno e desumano, reforçando na experiência do colonizador a ruptura, a perda de contato com tudo que pudesse o fazer recordar sua humanidade (FANON, 2008). Isso nos ajuda a começar a articular a "árvore do esquecimento", ao sequestro do ser, dos silenciamentos, apagamentos e esquecimento impostos às memórias negras e as heranças africanas na diáspora como necropolíticas das memórias negras. Procuravam ainda legitimar a ideia de um escravo amnésico, onde as comunidades negras seriam, além de excluídas da possibilidade de preocupação com a história, não no sentido de "sem história" ou contrário à história, mas sem historicidade, definidas como "povos sem memória".

Na passagem do século XIX para o XX e o processo de formação do Estado-nação brasileiro é importe retomar o que Franz Fanon fala sobre o fato dos discursos do colonialismo operarem com morte e vida em campos diametralmente opostos, de modo que nenhum povo que conheceu a civilização teria o direito de escolher a barbárie, lógica binária e não relacional em que civilização significa vida, ser lembrado e barbárie significa morte, ser esquecido.

No caso do Brasil, no pós-abolição, empreende-se um projeto de brasilidades gestado sob o mito da democracia racial e da mestiçagem, de viés branco, que seria o nosso pendor para o horizonte civilizado. Assim, o negro parecer habitar irregularmente esse mundo, porque este é um mundo de brancos, de um devir branco, embranquecido. Dentro do pacto-projeto nação não há espaço para os povos negros falarem de si mesmos.

As estratégias dos colonizadores em tentar controlar os mecanismos de gestão das memórias dos povos escravizados, entre lembranças e esquecimentos, é uma das facetas necropolíticas que gesta o não-ser e justifica a morte do ser negro na colonização, que é também a possibilidade da morte do corpo biológico, mas, sobretudo, a morte da memória, do passado, da sua história e ancestralidade, e assim a morte dos seus conhecimentos afrodiaspóricos.

Para chegarmos ao que estamos chamando de necropolíticas da memória negra [memoricídio] é necessário retornamos ao mito do escravo sem memórias. A produção de um escravo amnésico como fruto do sequestro e da produção da morte do ser é a tentativa do 
colonialismo de gestar um espaço para habitar o ser-colonial, subalternizado, sem memórias, impedido de ser, sem soberania existencial (PESSANHA, CUNHA PAZ \& SARAIVA, 2019, p.06; SODRÉ, 2017). "Este panorama cruel nos apresenta a possibilidade da construção de uma reflexão em que entendemos que determinadas vidas[o ser-que-era $\left.{ }^{5}\right]$ que antes detinham sua importância no continente africano, passaram a ser questionadas e pouco valorizadas perante o processo de colonização" (idem), além de identificar as diversas estratégias para a manutenção do seu cativeiro e da sua morte na diáspora sob a zona do não-ser (FANON, 2008).

$\mathrm{O}$ sequestro do ser [ser-que-era] criaria assim a imagem de uma despersonalização ou alienação que força os sujeitos negro-africanos/afrodiaspóricos a olharem para si a partir dos olhos do outro [desde fora], de uma ótica que os racializa, subalterniza e que dá a eles a perspectiva de referências e representações negativas, pejorativas, estereotipadas e inferiorizadas de si mesmo, o que pode gerar, em nossa leitura, alienação e trauma (KILOMBA, 2010).

Essa imposição colonial de uma "despersonalização" e de um olhar "desde fora" é fundamental para compreendermos que "durante a imposição do ser-colonial houve uma ruptura entre este ser-que-era e sua ancestralidade, transformando o ser-que-era em seresfacelado e a ancestralidade em uma ancestralidade-fragmentada" (PESSANHA, CUNHA PAZ \& SARAIVA, 2019, p.07).

Entendendo que o racismo é central para a compreensão do dito mundo moderno, é preciso descortinar essa lógica colonial que nega o status de humanidade ao corpo negro e as suas repercussões e seus agenciamentos de sociabilidade, de produção de subjetividade e de construção de memórias sobre a escravidão (MBEMBE, 2017; FANON, 2008/2006; CARNEIRO, 2005). Para Mbembe (2017) todos estes eventos incidirão sobre o ser de origem africana, ou ao sujeito que assim é percebido, onde quer que ele esteja. Raça como categoria que cinde a realidade entre negros e brancos.

A lógica colonial que nega a povos africanos e seus descendentes o status de seres humanos, ocasionaria duas mortes, a morte do corpo e do saber, que, para Pessanha (2018), são dois assassinatos conceitualmente identificados, respectivamente, como necropolítica e epistemicídio. Se “a noção de raça permite que se representem as humanidades não europeias

\footnotetext{
${ }^{5}$ Em Na travessia o negro se desfaz: vida, morte e memORía, possíveis leituras a partir de uma filosofia africana e afrodiaspórica de Eliseu Pessanha, Francisco Cunha Paz e Luís Saraiva os autores defendem a ideia que "Este ser-colonial se apresenta como detentor de uma agência de controle sobre tais vidas, sendo assim, nos faz aqui uma reflexão pertinente que nos coloca a pensar sobre um ser-que-era, este que detinha suas compreensões ontológicas da vida e da realidade. Ora, não podemos afirmar com total propriedade se este ser-que-era se traduz por um ser-africano, pois a África em sua grande multiplicidade não se enquadraria em um único ser” (2019, p.06).
} 
como se fossem um ser menor, um reflexo pobre do homem ideal" (MBEMBE, 2014, p. 39) ela nos permite entender como a lógica do racismo operou sobre as memórias, sobre o corpo que lembra, sobre o que é lembrado e sobre as formas e usos das narrativas criadas.

A construção do ser-que-era em não-ser, negro (CARNEIRO, 2005), estigmatizado, inferiorizado, indesejável, fez com que este fosse colocado em lugares subalternos, no lugar daqueles que não precisam ser lembrados, que deviam ser esquecidos, ou mesmo no lugar da morte como desencantamento, como perda da energia vital (SIMAS\&RUFINO, 2018).

É a partir das perspectivas produzidas pelos povos africanos e negro-africanos na diáspora, onde morte e vida não estão separadas, e vida é tida como parte da morte e a morte como parte incomensurável da vida, que sustentamos a ideia de que morrer não significa tão somente a morte biológica do corpo. Isso nos permite enxergar a tentativa de fazer morrer o conhecimento e as memórias gestadas por negros e negras, como a possibilidade de propor o uso do conceito de necropolítica para falar da produção da morte ontológica do ser negro na diáspora, forjada na sua impossibilidade de lembrar de si e narrar a si mesmo como elemento de reconstrução e sobrevivência/supra vivência. Nessa impossibilidade de lembrar como produção da morte ontológica do ser negro é que pensamos na necropolítica das memórias negras, especialmente as da escravidão.

E guiados nas discussões sobre genocídio de Abdias do Nascimento (1978) que começamos a articular a ideia de que não podemos pensar as políticas institucionais de memória no Brasil pós-abolição, ou as memórias públicas, tão somente apenas como políticas de esquecimento, mas também sob a perspectivas de que estamos definindo como necropolíticas das memórias negras, de extermínio das memórias para a consequente morte ontológica do ser negro.

Pode-se chamar de políticas da memória o conjunto de intervenções de atores públicos que objetivam produzir e impor lembranças comuns a uma dada sociedade, em favor do monopólio de instrumentos de ações públicas (comemorações oficiais, programas escolares de história, leis memoriais, panteões, etc.). A construção de uma narrativa coletiva feita pelos poderes públicos é parte integrante desse modo de ação pública. (MICHEL, 2010, p, $14)$.

A partir dessa definição defendemos a ideia de que a política de memória é também e necessariamente uma necropolítica da memória, isto é, por meio de um conjunto de políticas simbólicas, no qual se permitiria que os sujeitos criassem uma identificação como membros de um determinado grupo mais amplo, ao mesmo tempo em que se diferenciassem, se 
distanciassem, criando um outro divergente desta imagem idealizada e, portanto, excluído das narrativas oficiais e coletivas sobre a nação.

O que estamos chamando de necropolítica da memória seriam as ações do Estado [mas não só], cujas funções seriam as de tentar produzir uma imagem idealizada e consensual da ordem nacional, a fim de legitimar o poder exercido, nas esferas do Estado, pelo grupo dominante que se utilizaria de seus símbolos e narrativas como uma espécie de espelho ideologizante, a partir do silenciamento, apagamento e extermínio das memórias dos grupos subalternizados.

O corpo negro, seus valores e projetos civilizatórios africanos e afro-brasileiros na diáspora e toda essas heranças que estão nas esquinas, nos bares, nas ruas, na construção simbólica do espaço geográfico das cidades brasileiras, nos alimentos, no português como língua [pretoguês ${ }^{6}$ ], no cancioneiro, nas danças, nos cabelos, nas religiosidades, nunca foram esquecidas, mas constantemente lembradas e historicamente negadas, excluídas, expurgadas, subalternizadas e apagada nas narrativas das memórias da nação de pretensões hegemônicas.

Diante disso, o Estado brasileiro, enquanto agência colonial, se nega a assumir a raça como pressuposto que fundamenta a produção das suas políticas de memória. Ao fazê-lo, se omite, sendo reprodutor e mantenedor das violências e desigualdades seculares que procuram aprisionar as populações negras (SIMAS, 2018; MBEMBE, 2014/2018; CARNEIRO, 2005). O racismo, segundo Simas e Rufino (2018), para além de suas incontáveis faces opera de três maneiras: a) cor da pele; b) desqualificação dos bens simbólicos dos subalternizados; c) autoestima dos subalternizados, levando-os a introjetarem a percepção de inferioridade. Assim, compreendemos o racismo como esse fenômeno múltiplo e atualizável, "seja nas perspectivas epistêmicas/semióticas/simbólicas", mas sempre se vinculando com a presença e a existência negra, “o alvo é sempre uma produção negra” (SIMAS \& RUFINO, 2018, p.110).

A necropolítica da memória e a forma deliberada, organizada e planejada de apagamento e de esquecimento das memórias, das heranças e do passado negro da região portuária são também a produção da morte do ser, a morte do corpo negro que foi inserido no "pacto-projeto" da nação majoritariamente sob instauração da sua inferiorização e do seu lugar de subalterno.

Nos aproximamos então do conceito de genocídio do negro brasileiro de que fala Abdias do Nascimento. Para o autor, o genocídio negro se daria pelo:

\footnotetext{
${ }^{6}$ Definição da pensadora negra, Lélia Gonzalez, para as influências das africanas na fala de brasileira e brasileiros. “[...] aquilo que chamo de 'pretoguês' e que nada mais é do que a marca de africanização no português falado no Brasil [...]. (GONZALEZ, 1988, p.70).
} 
O uso de medidas deliberadas e sistemáticas (como morte, injúria corporal e mental, impossíveis condições de vida, prevenção de nascimentos), calculadas para a exterminação de um grupo racial, político ou cultural, ou para destruir a língua, a religião ou a cultura de um grupo (NASCIMENTO, 1978, p.17).

As necropolíticas da memória negra são também o que Nascimento (1978) definiu ainda nos anos de 1970 "como instrumentos que estão a serviço dos interesses das classes no poder e são usados para destruir o negro como pessoa, e como criador e condutor de uma cultura própria” (NASCIMENTO, 1978, p. 94). Abdias do Nascimento argumenta ainda que a miscigenação funciona como uma forma de dizimar a raça negra no Brasil, portanto uma necropolítica da memória negra.

Para o autor, "as leis de imigração nos tempos pós-abolicionistas forma concebidas dentro da estratégia maior: a erradicação da "mancha negra" na população brasileira" (NASCIMENTO, 1978, p. 71). À miscigenação deveria ser aproximada outra estratégia de genocídio do negro, e também de uma necropolítica da memória negra, o "embranquecimento cultural", que segundo o autor é como são definidas aculturação ou assimilação cultural. O desencantamento da memória como desencantamento do ser.

\section{MemORÍa e a recuperação das memórias usurpadas pelo colonialismo}

As palavras de Beatriz Nascimento em seu poema "Sonho", e que abrem este ensaio, nos lançam inevitavelmente a pensar a ideia de testemunho, de um corpo-testemunho, de um corpo como documento, um corpo como território. Onde os sulcos, caminhos, nos narram tanto experiências, sentimentos, medos e desejos vivenciados pelos sujeitos negros na diáspora, quanto nos permitem cartografar os caminhos construídos por negras e negros para na travessia se refazerem, se reconstruírem como sujeito, como pessoa. Nos permitem perceber as heranças históricas presentes nos esforços de reconstrução do ser negro-africano dilacerado pelo colonialismo.

São marcas que comunicam chagas, feridas históricas, traumas, mas que permitem a observação dos caminhos abertos para pensar o presente, e um futuro. Mais que isso, nos obriga a rememorar o passado a partir do presente, projetando "agoras", devires, futuros. Nos leva a dobrar o tempo a partir do encanto, do afetamento, do sentimento de ouvir e partilhar narrativas. Como bem costurou Wanderson Flor do Nascimento, sem a possibilidade de sentir pouco produtiva seria ouvir sobre as marcas, pistas, rastros e testemunhos que carregam os corpos negros, "sem nos afetarmos sobre o que aprendemos, o saber de nada adianta, aliás, nem é saber, é mera informação" (FLOR do NASCIMENTO, 2019, p.29). 
Pensar o afeto, não como código, ou algo dado, mas como um processo dinâmico, um projeto político, o "afetar-se" como uma agência. Uma recusa ao ódio, mas não uma negação das marcas, dos traumas ou daquilo que nos oferece a história. É pensar o corpo como território, como lócus da produção de territorialidades, de narrativas. Beatriz do Nascimento (1989) nos leva a repensar e a reposicionar a dor a partir da perspectiva do trocar com o outro a experiência do sofrer, do exilio, reposicionando a dor como algo que nos atravessa e nos liga. Para a autora, esse corpo negro pode ser, então, aquele que porta carências radicais de liberdade, mas que procura e constrói lugares de referência transitórios ou duradouros. (FLOR do NASCIMENTO, 2019; PIEDADE, 2017; NASCIMENTO, 1989).

Os sulcos da face como caminho do mundo, da forma como se apresenta no poema, remete a imagem de Glissant (2005), do migrante nu e permite entender que entre o lugarpassado e o lugar-presente, africanos e seus descendentes perpetuam a partir de recriações e reconstruções suas culturas, cosmologias e experiências. Além da memória, o corpo pode ser apontado como essa outra "bagagem", um ancorador de memórias e heranças, que Alex Ratts em diálogo e encruzo com Beatriz do Nascimento define como "corpo-documento", o "principal documento dessas travessias, forçadas ou não" (RATTS, 2007, p.68). Corpo este que é o local concreto de sofrimento (BELL HOCKS, 2008, p.860) e da narrativa sobre a dor e o sofrimento (PIEDADE, 2017), nos oportunizando entender o negro como lugar das lembranças, das memórias e das narrativas dentro de uma perspectiva antirracista de reconstrução e de afirmação do próprio negro, procurando desfazer o cativeiro do "lugar do negro" denunciado por Lélia Gonzalez (1984).

Qual o lugar do negro? é preciso entrar em guerra contra o negro produzido pelo colonialismo, fruto de um mito perverso do escravo amnésico. Pensar "Desde a travessia" é nos aproximar de Beatriz do Nascimento (2006), que a partir de suas leituras de Lélia Gonzales e a crítica da autora ao lugar natural aristotélico, procura romper com a imaginário do "Lugar do negro" definido em relação ao "centro do universo", no caso o universalismo-branco-europeu, afirma que:

“[...] um lugar de negros" [...] Não constituem apenas encontros corporais. Trata-se de reencontros de uma imagem com outras imagens no espelho: com negros, com brancos, com pessoas de outras cores e compleições físicas e com outras histórias (RATTS, 2006, p.68)

As autoras, apesar de usarem a categoria "lugar do negro" para se referir aos diferentes modos de dominação do corpo e do ser negro na diáspora, procuram romper com a ideia de 
lugar natural aristotélico, onde as coisas se posicionam em relação a um centro. No caso específico lembrado por Lélia e Beatriz, o centro do universo social, intelectual e racial, seria o universalismo ocidental europeu e branco.

A fim de acometer em fuga desse lugar nos propomos pensar em "travessia" (BIDIMA, 2002), e "Desde a travessia" (CUNHA PAZ, 2019; CUNHA PAZ, PESSANHA \& SARAIVA, 2019), e desde um corpo e uma cosmosensação/cosmopercepção [corpus] atlântica, ou ainda do que Paul Gilroy (2012) chamou de "Atlântico Negro", é pensar também a possibilidade sobre a relevância, e não centralidade, de África, na reconfiguração social, cultural, político e ontológica do Atlântico Sul ou Atlântico Ocidental.

Pensar a memória desde a travessia é perceber que as diversas lembranças, heranças e tradições africanas e afro-brasileiras, mesmo rasuradas, silenciadas e folclorizadas, provocaram e provocam fraturas na modernidade e na colonialidade e, marcam presença até os dias de hoje nas fronteiras (BHABHA, 1998), nas brechas, no avesso. Estão assentadas na memória das palavras, dos corpos e dos espaços (ANTONNACI, 2014).

Elementos como a palavra, oralidade, corpo, espaço, podem nos permitir a pensar a constante presença do passado, rompendo ou podendo romper com a divisão clássica passado/presente/futuro como tempos subsequentes. Assim, a partir da perspectiva de pensamento de rastros/resíduos de Glissant (2008) é possível reunir elementos e rastrear as dispersas tradições africanas no Brasil e afro-brasileiras. Bem como articular sinais tangíveis de interações preservadas corpo-a-corpo e mapear as práticas sociais e culturais, manifestações, celebrações e festas, as redes de comunicações e interações com o espaço e com a cidade, produzidas por africanas e africanos e afro-brasileiras/os ao longo do tempo.

O pensamento de rastros/resíduos nos permite identificar no interior das memórias da escravidão modos de ser, estar, pensar e sentir dos negros, que escapavam aos domínios senhoriais e que escapam aos silenciamentos e esquecimentos impostos. E permite ainda, propor categorias como Corpo-memórias, território-memória e corpo-território de uma tradição viva (HAMPÂTÉ BÂ, 2008), que se contrapõem à visão reducionista que pensam os corpos da humanidade africana e ameríndia como mero portadores de culturas, memórias e narrativas inferiores, o que os colocaria a serviço do homem civilizador. (ANTONACCI, 2014; HAMBÂTÉBÂ, 2008; GLISSANT, 2005).

Isso posto, e tomando a ancestralidade como um valor de mundo para os povos africanos e afrodiaspóricos, estamos propondo um outro conceito de Memória, ligado ao Orí, este que 
que seria o mais profundo elo com as ancestralidades africanas, a MemORÍa, que pode ser definida como:

[...] um conceito-potência, que ao recorrer ao passado, ao reverenciá-lo, garante o futuro, gera o porvir, mas não numa concepção ocidental linearcausal de tempo e espaço. Este conceito é um esforço de tentar demonstrar como passado, presente e futuro não existem desta maneira como temporalidades agonizantes, mas que estabelecem entre si uma relação de sucessão não linear dos acontecimentos e de atribuição mútua de sentido. Não se trata, também, de pensar que memória é o que resta do passado no presente, ou o que restará no futuro, pelo contrário, a ideia de memÓRÍa nos faz pensar como essa divisão passado, presente e futuro não existe nestes termos dentro de uma ontologia africana no Brasil encontrada nos candomblés brasileiros, por exemplo (CUNHA PAZ, PESSANHA \& SARAIVA, 2019, p.114).

Este é um conceito de memória que se coloca para a dialogar com os esforços dos povos e comunidades negras na diáspora a fim de potencializar os seus esforços de reconstrução do ser negro esfacelado pelo colonialismo e a escravidão. Como um esforço de restituir a lembrança, a memória e a história do ser africano e seus descendentes negros na diáspora, aos próprios negros.

Onde a MemORÍa também é constituída de memória, onde não há, portanto:

[...] como fazer investigações sobre este ser-que-era, o ser-esfacelado e o sernão-sendo sem aceitar que tanto a memòRÍa e Ntu se componham enquanto agenciamentos do próprio pensar. Tal efeito nos permite dizer que tudo no universo possui memória. A vida, por sua vez, também é uma extensão da memória, onde o território da memória poderia vir a ser o território do sersendo, que vai libertar do cativeiro colonial o ser-negro da escravidão. Este movimento, [feito em travessias], é o ser-sendo em que memÒRÍa será essa força motriz que possibilitaria a reconstrução do ser-esfacelado e a ancestralidade-fragmentada da colonização (CUNHA PAZ, PESSANHA \& SARAIVA, 2019, p.118).

Um conceito que pretende se inserir no campo das disputas políticas e das lutas antirracistas tendo em vista que nasceu na diáspora e com bases nas filosofia(s) africana(s) e afro-diaspóricas. Tem suas bases na ontologia e numa metafísica da memória, que também é um campo de disputa política. A ideia de MemORÍa como conceito e um esforço político nos lembra que esquecer e lembrar podem não ser escolhas.

MemORÍa como a possibilidade de agenciar um lembrar negro do negro, fugindo das armadilhas de incorrer num possível etnocentrismo ou mesmo na busca por uma identidade negra essencializada. Pelo contrário, é pensar num conceito de memória a partir de uma cosmologia de perspectiva africana ou afrodiaspórica que nos diz menos sobre fronteiras 
geográficas e mais sobre processos, destacadamente distantes dos modos eurocêntricos, coloniais, tanto possíveis analogias.

Trata-se de um esforço de lembrar, de recuperar uma narrativa do passado que é anterior, sobrevive e é reinventada durante escravidão. MemORÍa, longe de representar a procura por uma redenção absoluta, o que de antemão parece impossível, é antes uma tentativa de romper com a ideia anteriormente apresentado, do ser negro produzido pela colonização e pela modernidade, amnésico, sem história, sem passados, sem memórias e desencantado.

\section{Tecendo considerações parciais}

Ao passo que o Brasil é a escravidão negra, com dito na abertura deste ensaio, os negros afrodiaspóricos e afro-brasileiros não resumem suas experiências à escravidão atlântica, existem para além do cativeiro colonial que esfacelou o ser negro-africano durante mais de três séculos. A ideia de pensar a memória e o passado em relação com ancestralidade permite repensar e reposicionar os estudos de memória social e coletiva, as formas de relação com o passado, tempo e mesmo a escrita da história.

Neste ensaio apresentamos o conceito de MemORÍA, isto é, uma ideia de memória criada a partir de um cosmosensação produzida desde os repertórios culturais africanos e afrodiaspórico, que reconhece referenciais outros, inclusivos, diversos, dinâmicos, solidários, recupera a ancestralidade negro-africana, seus valores, conquistas e epistemologias como possibilidade de tirar negros e negras do lugar do "não-ser" amnésico gestado pelo cativeiro colonial e pela escravidão negra.

Pensar uma categoria de memória como um exercício de um lembrar negro do negro, que permita aos negros e negras se refazerem para além das dores, das chagas, marcas e traumas da colonização e do escravismo, isto é, reconstruir a si mesmo. Memória como um lembrar de si, um narrar a si mesmo, compreendendo a escrita de si como estratégia de movimentar-se ancestralmente para além da dor, mas sem negá-la, sem oblitera-la das linhas escritas, faladas ou performadas.

MemORÍa como o esforço em dizer que não basta apenas inserir personagens e narrativas sobre personagens negros e negras que foram excluídos ou marginalizados nas histórias e narrativas de memórias oficiais. Mas que é preciso uma virada epistêmica que possa combater no campo de mandinga e no campo de batalha (RUFINO \& SIMAS, 2017), o racismo epistêmico. E que isso passa pela recuperação e o reconhecimento de uma cosmologia negro-

africano, em África e na diáspora, que "imagina-cria-inventa" e nos diz sobre um universo 
povoado de diferentes tipos de agências e de subjetividades, nas quais humanos e não-humanos, em relação de interdependência, são dotados de um tipo genérico de força/energia vital o que pode nos permitir pensar perspectivas históricas antirracistas, de afroperspectivas, ancestrais e de encantamento.

É pensar, alinhados a Beatriz Nascimento (1989), que a história, a memória e por fim, o passado, aparecem como a possibilidade de reconstrução do ser negro no Brasil após seu estilhaçamento durante a colonização, a escravidão e o racismo da democracia racial. Ou ainda, na mesma linha defendida pela psicanalista negra, Neusa dos Santos Souza, "uma das formas de exercer autonomia é possuir um discurso sobre si” (SOUSA, 1983. p. 17), uma escrita de si. É partir deste encantamento que este ensaio procura oferecer um outro conceito de memória e convida aos pesquisadores, negros e negras, dedicados aos estudos negros ou sobre o negro a pensar a respeito de um lembrar negro sobre o negro e da "construção de um discurso [narrativa] negro sobre o negro" (Idem).

\section{Referências}

AGUESSY, Honorat. Visões e percepções tradicionais. In: SOW, Alpha I et. al. Introdução à cultura Africana. Lisboa: Edições 70, 1980.

AJARI, Norman. Frantz Fanon: luchar contra la bestialización, demolir el biopoder. Revista anual de la Unidad de Filosofía Práctica e Historia de las Ideas / INCIHUSA - CONICET, Vol. 13 / ISSN 1515-7180, 2011, p.53-60.

ANTONACCI, Maria Antonieta. Memórias ancoradas em corpos negros. São Paulo: EDUC, 2013.

BHABHA, Homi K. O local da cultura. 5.reimp., Belo Horizonte: Editora UFMG, 2010.

BEIGUELMAN, Giselle. Da escravidão à ditadura, esquecimento é marca do Brasil. Entrevista à Folha de São Paulo em 10 de Agosto de 2019. Disponível em

BIDIMA, Jean-Godefroy. De la traversée: raconter des expériences, partager le sens. Rue Descartes, n. 36, p. 7-17, fev-2002.

CARNEIRO, Aparecida Sueli. A construção do outro como não-ser como fundamento do ser. Tese de Doutorado. 2005. 339f. Programa de Pós-graduação em Educação. USP. São Paulo, 2005.

CUNHA PAZ, Francisco Phelipe. Na casa de Ajalá: comunidades negras, patrimônio e memória contracolonial no Cais do Valongo - a "Pequena África". Dissertação de Mestrado apresentada no Programa de Pós-Graduação em Desenvolvimento, Sociedade e Cooperação Internacional - UnB, 2019. 
CUNHA PAZ; PESSANHA; Eliseu \& SARAIVA, Luis Augusto Ferreira. Na travessia o negro se desfaz: vida, morte e memÓRÍa, possíveis leituras a partir de uma filosofia africana e afrodiaspórica. Voluntas, Santa Maria, v. 10, p. 110-127, set. 2019. Disponível em: https://periodicos.ufsm.br/voluntas/article/view/39949

EVARISTO, Conceição. Literatura e educação segundo uma perspectiva afro-brasileira. In: EVARISTO, Conceição; SILVA, D. (Orgs.). Literatura, história, etnicidade e educação: estudos nos contextos afro-brasileiros, africano e da diáspora africana. Frederico Westphalen: URI, 2011. p. 45-54.

Becos da Memória. Belo Horizonte: Mazza, 2006.

EZE, Emmanuel Chukwdi. La moderna filosofia occidental y el colonialismo africano. In: EZE, Emmanuel Chukwudi (Org.). Pensamiento africano. Barcelona:Edicons Bellaterra, 2001.

FANON, Frantz. Pele Negra, Máscaras Brancas. Tradução de Renato de Silveira. Salvador: EDUFBA, 2008.

FLOR do NASCIMENTO, Wanderson. Ori: a saga atlântica pela recuperação das identidades usurpadas. In: SOUZA, Edileuza Penha de. Negritude, Cinema e Educação. Belo Horizonte: Mazza, 2007.

. Outras vozes no ensino de filosofia: O pensamento africano e afro-brasileiro. Revista Sul-Americana de Filosofia e Educação, n 18, p. 74-89, 2012.

Aproximações brasileiras às filosofias africanas: caminhos desde uma ontologia ubuntu. Prometeus, n 21, Dez. 2016.

GILROY, Paul. Atlântico Negro: modernidade e dupla consciência. Tradução de Cid Knipel Moreira. São Paulo: Editora 34, 2012.

GLISSANT, Édouard. Poética da Relação. Tradução de Manuela Mendonça. Porto: Porto Editora, 2011.

Introdução a uma poética da diversidade. Juiz de Fora: Editora UFJF, 2005.

GONZALEZ, Lélia. A categoria político-cultural de amefricanidade. In: Tempo Brasileiro. Rio de Janeiro, Nº. $92 / 93$ (jan./jun.) p. 69-82, 1988.

GUIMARÃES, Geny Ferreira. Rio Negro de Janeiro: olhares geográficos de heranças negras $e$ o racismo no processo-projeto patrimonial. Tese de Doutoramento apresentada à Universidade Federal da Bahia - UFBA, Salvador, 2015.

HAMPÂTÉ BÂ, AMADOU. A Tradição Viva. In: KI-ZERBO, Joseph. História geral da África I: Metodologia e pré-história da África. Brasília: UNESCO, 2010. 
HOOKS, Bell. Moving Beyond Pain. Tradução: Charô Nunes e Larissa Santiago. Blogueiras Negras. Disponível em: http://blogueirasnegras.org/2016/05/11/movimentar-se-para-alem-dador-bell-hooks/.

KILOMBA, Grada. Plantation Memories: Episodes of Everyday Racism. Münster: UNRAST - Verlag, 2010.

INIKORI, J. E. A África na história do mundo: o tráfico a partir da África e a emergência de uma ordem econômica no Atlântico. In: OGOT, Bethwell Allan. História geral da África, $V$ : África do século XVI ao XVIII. Brasília: UNESCO, Vol 5, História Geral da África: a Ấfrica do século XVI ao XVIII, 2010.

MBEMBE, Achille. Formas Africanas de Auto-inscrição. Estudos Afro-Asiáticos, nº 1, 2001. . Crítica da Razão Negra. Tradução de Marta Lança. Lisboa: Antígona, 2014. . Necropolítica. Rio de Janeiro: N-1 edições, 2016.

MICHEL, Johann. Podemos falar em uma política do esquecimento? Revista Memória em Rede, Pelotas, v.2, n.3, ago-nov. $2010 \quad-\quad$ ISSN- 2177-4129 www.ufpel.edu.br/ich/memoriaemrede.

NASCIMENTO, Abdias do. O Genocídio do Negro Brasileiro: Processo de um Racismo Mascarado. Rio de Janeiro: Paz e Terra, 1978.

NASCIMENTO, Beatriz. Filme Ori (texto). Direção: Raquel Gerber. São Paulo, Angra Filmes, $131 \mathrm{~min}, 1989$.

OLIVEIRA, E. O. Cosmovisão Africana no Brasil: elementos para uma filosofia afrodescendente. Fortaleza: LCR, 2003.

OYĚWÙMÍ, Oyèrónkẹ. The Invention of Women: making an African sense of western gender discourse. Minneapolis: University Minnesota Press, 1997.

PESSANHA, Eliseu Amaro de Melo. Necropolítica \& epistemicídio: as faces ontológicas da morte no contexto do racismo. Dissertação de Mestrado apresentada no Programa de PósGraduação em Metafísica na Universidade de Brasília - UnB, 2018.

PIEDADE, Vilma. Dororidade. São Paulo: Editora, 2017.

RAMOS, Guerreiro. Introdução crítica à sociologia brasileira. Rio de janeiro: Editora UFRJ, 1995.

RAMOSI, Mogobe Bernard. A importância vital de nós. Revista IHU, dez. 2010. Disponível em http://www.ihuonline.unisinos.br/artigo/3688-mogobe-ramose.

RATTS, Alex. Eu sou atlântica: sobre a trajetória de vida de Beatriz Nascimento. São Paulo: Instituto Kuanza/Imprensa Oficial, 2007. 
SARAIVA, Luis Augusto. Sobre veias d'águas e segredos da mata: Filosofia Ubuntu no Terreiro de Tambor de Mina. Dissertação de Mestrado - Universidade de Brasília, Instituto de Ciências Humanas, Programa de Pós-Graduação em Metafísica, 2018.

SCHWARCZ, L. GOMES, F. (OrgS). Dicionário da escravidão e liberdade. São Paulo: Companhia das Letras, 2018.

SIMAS, Luiz Antônio \& RUFINO, Luiz. Fogo no Mato: a ciência encantada das macumbas. Rio de Janeiro: Mórula, 2018.

SODRÉ, Muniz. Pensar Nagô. São Paulo: Editora Vozes, 2017. 